American Medical Journal 2 (2): 59-64, 2011

ISSN 1949-0070

(C) 2011 Science Publications

\title{
Antidepressant-Like Activity of Banana Peel Extract in Mice
}

\author{
Tan Pei Tee and Halijah Hassan \\ Department of Health Sciences, \\ Faculty of Health and Life Sciences, Management and Science University, \\ University Drive, Off Jalan Persiaran Olahraga, Seksyen 13, \\ 40100 Shah Alam, Selangor Darul Ehsan, Malaysia
}

\begin{abstract}
Problem statement: Depressed mood, loss of interest or pleasure, feeling guilty, low selfesteem, sleep disturbance, loss of appetite, low energy and poor concentration are the characteristics of depression. This common mental disorder can occur in anyone regardless of genders, ages and backgrounds. People counteract it with psychotherapy and medications. Alternatively, some patients use herbal remedies as treatments. Recently, natural herbal products that have antidepressant effect has gain more attention in the market. Banana peel is commonly used to treat warts, as diuretics, aids in detoxification and relive hangovers. This research was conducted to study the effects of banana peel extract against depression. Approach: Swiss Albino mice were used in this study. Acute Toxicity Study (ATS) was being carried out by injecting 4 doses of the green and yellow banana peel extract each to different mice groups. Six groups of mice were treated with different treatments (normal saline $5 \mathrm{~mL} \mathrm{~kg}^{-1}$, green banana peel extract 200 and $400 \mathrm{mg} \mathrm{kg}^{-1}$, yellow banana peel extract 200 and $400 \mathrm{mg}$ $\mathrm{kg}^{-1}$, Fluoxetine $\mathrm{HCl} 20 \mathrm{mg} \mathrm{kg}^{-1}$, p.o.) for 7 consecutive days before mice were subjected for Forced Swim Test (FST) and Tail Suspension Test (TST). Results: The result shows that green banana peel extract $400 \mathrm{mg} \mathrm{kg}^{-1}$ significantly reduces the duration of immobility $(\mathrm{p}<0.01)$ compared to control in FST. In TST, green banana peel extract $400 \mathrm{mg} \mathrm{kg}^{-1}$ and yellow banana peel extract (200 and $400 \mathrm{mg}$ $\mathrm{kg}^{-1}$ ) showed significant result $(\mathrm{p}<0.001)$ compared to control. There were no signs of acute toxicity observed for the extracts in ATS. Conclusion/Recommendations: This research suggested that the banana peel extracts exhibits antidepressant-like effects. Further studies maybe conducted on locomotor activity study and phytochemical screening.
\end{abstract}

Key words: Tail Suspension Test (TST), banana peel, Forced Swim Test (FST), antidepressant activity, Acute Toxicity Study (ATS)

\section{INTRODUCTION}

Depression is a significant public health problem that can occur to anyone and are likely to occur on adults in between the age of 20-50 years old with no relations to race, education status, civil status or income (WHO, 2010; Khandelwal et al., 2001). According to World Health Organization, depression affects about 121 million people worldwide and it is among the leading cause of disability worldwide as measured by Years Lived with Disability (YLDs). In year 2000, depression is the fourth leading contributor to the global burden of disease. It is predicted that by the year 2020, depression is projected to reach second place of the Disability Adjusted Life Years (DAYLs) ranking calculated for all ages and both sexes. Depressions are often results from a combination of factors such as genetics, biochemical, environmental and psychological factors but sometimes it can appear without apparent reason or triggers (NIMH, 2008; MPA, 2006). Depending on the nature and severity of the symptoms, depression is classified into mild, moderate and severe depression (NIMH, 2008; American Psychiatric Association DSMV-IV, 2000). It can be reliably diagnosed and treated in primary care, the treatment with medication and brief structured psychotherapy is effective for $60-80 \%$ of those affected by depression however fewer than $25 \%$ of the affected people have access to the effective treatments (WHO, 2010). Several classes of antidepressant are being used to treat depressions but they have side effects such as blurred vision, restlessness, nervousness, sexual problems, agitation and suicidal thoughts (Department of Health and Ageing, 2003; Kahn et al., 2001; NIMH, 2008). To

Corresponding Author: Tan Pei Tee, Department of Health Sciences, Faculty of Health and Life Sciences, Management and Science University, University Drive, Off Jalan Persiaran Olahraga, Seksyen 13, 40100 Shah Alam, Selangor Darul Ehsan, Malaysia 
reduce the impact of depression, there is an urge to provide a cost effective treatment to the public. With the increase incident of depression, natural herbs that have antidepressant effect has gain more attention recently as alternative treatment for depression. Banana peels consist $30 \%$ of the weight of the fruits. The peel contains mainly dietary fibers. Other nutrients contain inside banana peels are proteins, fats, starch contents, potassium, iron, calcium and others inorganic elements (Chen et al., 2007). In this present study, the effect of Cavendish banana peel extract in treating depressed mice was being investigated by employing Forced Swim Test (FST) and Tail Suspension Test (TST). The standard drug, fluoxetine which is a selective serotonin reuptake inhibitor was used as positive control to compare the efficacy of banana peel extract as antidepressant.

\section{MATERIALS AND METHODS}

Banana peel extraction: The green banana peel extract was extracted by using the peel of fresh banana fruitMusa, AAA cv. Cavendish $(600 \mathrm{~g})$ at green with a trace of yellow stage, heated in $1 \mathrm{~L}$ of distilled water $\left(80^{\circ} \mathrm{C}\right)$ for $2 \mathrm{~min}$. The peel was homogenized with $70 \%$ acetone twice at room temperature using an electric blender (Mokbel and Hashinaga, 2005). Later it was centrifuged at $6000 \mathrm{rpm}$ for $10 \mathrm{~min}$. The $70 \%$ acetone green banana peel extracts are then filtered and concentrated to $300 \mathrm{~mL}$ using rotary evaporator at $50^{\circ} \mathrm{C}$. Then, the extract was allowed to dry overnight in an oven $\left(50^{\circ} \mathrm{C}\right)$. The yellow banana peel was also extracted by the same method. At the end, it yields $5.7282 \mathrm{~g}(0.96 \%)$ of dry matters green banana peel extract and $6.9014 \mathrm{~g}(1.15 \%)$ of yellow banana peel extract respectively.

Experimental animals: Ninety six Swiss albino mice of either sex (15-30g) were obtained from the lab. Animals were house in plastic cages at an ambient temperature $\left(25 \pm 2^{\circ} \mathrm{C}\right)$. A $12: 12 \mathrm{~h}$ light-dark cycle is maintained during the experiments. They were feed with balanced rodent pellet diet and water ad libitum throughout the experimental period. Animals were acclimatized to their environment for at least one week before experimentation. The animals were randomly divided into different groups.

Acute Toxicity Study (ATS): The female Swiss albino mice were fasted for $3 \mathrm{~h}$ prior to the experiment. Acute toxicity study was being carry out by injecting 4 dose $\left(0.25,0.50,0.75\right.$ and $\left.1.00 \mathrm{~g} \mathrm{~kg}^{-1}, \mathrm{p} . \mathrm{o}\right)$ of the green and yellow banana peel extract each to different mice groups $(n=3)$. The mortality and general behavior of the mice was observed for $48 \mathrm{~h}$ (Velraj et al., 2009) with special attention to the first $30 \mathrm{~min}$ and the first $4 \mathrm{~h}$ after the single oral administration, then periodically during the $48 \mathrm{~h}$ and daily for a total of 2 weeks (OECD, 2001; Gatsing et al., 2010).

Forced Swim Test (FST): The animal was divided into six groups and each group comprised of six mice. The treatment was given once daily for 7 consecutive days before the day of experiment (Table 1). Banana peel extract and fluoxetine were dissolved in normal saline. On the test day, the mice was forced to swim individually in a glass jar $\left(25 \times 12 \times 25 \mathrm{~cm}^{3}\right.$ sub $)$ containing fresh water of $15 \mathrm{~cm}$ height and maintained at $29^{\circ} \mathrm{C}\left( \pm 2^{\circ} \mathrm{C}\right)$ after $60 \mathrm{~min}$ of the administration of last dose (Bergner et al., 2010; Cryan et al., 2005). Two mice were being tested simultaneously by setting the apparatus side by side and blocked with a nontransparent screen to prevent the mice from seeing each other. After an initial 2 min period of vigorous activity, each animal assumed a typical immobile posture. A mice was considered to be immobile when it remained floating in the water without struggling, making only minimum movements of its limbs necessary to keep its head above water. The total duration of immobility was recorded with a webcam during the next 4 min of a total 6 min test. The changes in immobility duration were studied and compared after administering drugs in separate groups of animals. The water was changed to fresh water after each session to eliminate excrement, urine and fur. Each animal was used only once (Velraj et al., 2009; Kalra et al., 2008).

Tail Suspension Test (TST): The animal was divided into six groups and each group comprises six mice. The treatment was given once daily for 7 consecutive days before the day of experiment (Table 2). Banana peel extract and fluoxetine were dissolved in normal saline. Mice was suspended on a horizontal rod $50 \mathrm{~cm}$ above the surface of the table by adhesive tape placed approximately $1 \mathrm{~cm}$ from the tip of the tail on the test day after 60 min of the administration of last dose. The total duration of immobility induced by tail suspension was measured as a facile means of evaluating potential antidepressants. Immobility time was recorded with a webcam during a 6 min. period. Animal was considered to be immobile when it did not show any movement of body and hanged passively (Bergner et al., 2010; Cryan et al., 2005). Mobility was defined as movement of the hind legs (Velraj et al., 2009; Gopalakrishna et al., 2010). 
Table 1: Treatments for Forced Swim Test (FST)

\begin{tabular}{ll}
\hline Group $(\mathrm{n}=6)$ & Treatment (p.o) \\
\hline FST 1 (Control) & Normal saline $5 \mathrm{~mL} \mathrm{~kg}^{-1}$ \\
FST 2 & Green banana peel extract $200 \mathrm{mg} \mathrm{kg}^{-1}$ \\
FST 3 & Green banana peel extract $400 \mathrm{mg} \mathrm{kg}^{-1}$ \\
FST 4 & Yellow banana peel extract $200 \mathrm{mg} \mathrm{kg}^{-1}$ \\
FST 5 & Yellow banana peel extract $400 \mathrm{mg} \mathrm{kg}^{-1}$ \\
FST 6 & Prozac 20 mg kg-1 \\
\hline
\end{tabular}

Table 2: Treatments for Tail Suspension Test (TST)

\begin{tabular}{ll}
\hline Group $(\mathrm{n}=6)$ & Treatment (p.o) \\
\hline TST 1 (Control) & Normal saline $5 \mathrm{~mL} \mathrm{~kg}^{-1}$ \\
TST 2 & Green banana peel extract 200 mg kg \\
TST 3 & Green banana peel extract $400 \mathrm{mg} \mathrm{kg}^{-1}$ \\
TST 4 & Yellow banana peel extract 200 mg kg \\
TST 5 & Yellow banana peel extract $400 \mathrm{mg} \mathrm{kg}^{-1}$ \\
TST 6 & Prozac 20 mg kg-1 \\
\hline
\end{tabular}

Data collection: The result of FST and TST was recorded and scored the duration of immobility by a blind observer using JWatcher version 1.0 (University of California, Los Angeles, USA and Macquarie University, Sydney, Australia. Available at http://www.jwatcher.ucla.edu/). For ATS, the mice were observed for $48 \mathrm{~h}$.

Data analysis: The data obtain was analyzed by Oneway ANOVA (SPSS version 18) and followed by Dunnett's multiple comparison tests. $\mathrm{P}$ values below 0.05 were considered statistically significant. All the result obtains are express as mean \pm SEM.

\section{RESULTS}

Acute toxicity study: All of the mice used in this study did not show any sign of acute toxicity during the $48 \mathrm{~h}$ observation. The general behavior of the mice was normal. Mice did not show any problem in locomotion, reacted normal to noise and pinch, the tail was flexible.

Forced swim test: The result of the antidepressant effects of green banana peel extracts and yellow banana peel extracts was presented in Fig. 1. It shows that the green and yellow banana peel extracts at dose 200 and $400 \mathrm{mg} \mathrm{kg}^{-1}$ significantly decreased the immobility time of mice compared to control group.

Tail suspension test: The effects of the green banana peel extracts and yellow banana peel extracts as antidepressant in mice was presented in Fig. 2. It was revealed that the green banana peel extracts and yellow banana peel extracts at dose 200 and $400 \mathrm{mg} \mathrm{kg}^{-1}$ had significantly increased the duration of mobility in the tested mice.

\section{DISCUSSION}

Depression is a senile neurological disorder that is widely prevalent to modern fast paced life. Stressful lifestyle facilitates the evolution of depressive disorder as the stress can influence the function of central nervous system by altering a number of neurotransmitters, endocrine and neuroendocrine systems (Gopalakrishna et al., 2010). The most lethal complication of depression is the suicidal behavior (Khandelwal et al., 2001; Sudhakar et al., 2010). Despite the widely use of synthetic drugs to treat depression, these drugs often associated with adverse effects and limitations. The search for a natural product with fast onset of action, wide safety margin and less side effects has come to attention. The effective components of herbs that have antidepressant-like effect includes flavonoid, oligosaccharide, polysaccharide, alkaloid, organic acid (Velraj et al., 2009). The present study was designed to elucidate the effect of banana peel extract in treating depression in mice.

Forced Swim Test (FST) developed and Tail Suspension Test (TST) developed induces unavoidable stress to rodents which reflects a state of behavioral despair that is similar to human depression. A normal animal tested in FST and TST submitted to a non-soluble aversive situation shows alternate between agitation and immobility. The agitation reflects state of searching which requires energy consumption while immobility is energy conservation (Badhe et al., 2010). The uses of animal model are widely used as preclinical screening for antidepressant (Gopalakrishna et al., 2010; Sharma et al., 2009). Animals that are treated with antidepressants struggle more even in desperate situation and spend less time with immobility (Badhe et al., 2010).

Acute toxicity study: ATS is the first step in the toxicological analysis of herbal drugs (Mustaffa et al., 2010). In ATS, all of the mice survived during the $48 \mathrm{~h}$ observation. The general behavior of the mice during the study was found to be normal. There was also no delayed death during the 14 days observation. There was no mortality observed even at the high dose of $1.00 \mathrm{~g} \mathrm{~kg}^{-1}$, the Lethal Dose $50\left(\mathrm{LD}_{50}\right)$ of the green banana peel extract and yellow banana peel extract was found to be more than $1 \mathrm{~g} \mathrm{~kg}^{-1}$. Hence, the green banana peel extract and yellow banana peel extract were found to be safe up to a dose of $1 \mathrm{~g} \mathrm{~kg}^{-1}$ taken in a single dose via oral route. 
Forced swim test: FST is a drug screening test for antidepressants, it is able to detect activity of a broad spectrum of clinically effective antidepressants (Cryan et al., 2005). FST has a high degree of predictive validity to major class of antidepressants such as Tricyclic Antidepressants (TCAs), monoamine oxidase inhibitors (MAOIs), atypical antidepressant, Selective Serotonin Reuptake Inhibitors (SSRIs) and electroconvulsive therapy (Woode et al., 2010). This preclinical test evaluates the behavioral despair, a measure of failure to seek escape from an aversive stimulus in the tested mice. The immobility time is considered as the measure of depression-like behaviors, whereas, the reduction in the duration of immobility is characterized as antidepressant response (Woode et al., 2009; 2010). In Fig. 1, oral administration of green banana peel extract $200 \mathrm{mg} \mathrm{kg}^{-1}$ produced significant effect $(150.00 \pm 4.82$ mean \pm SEM, $\mathrm{p}<0.05)$ in mice when compared with control group that were treated with normal saline. The reduction of the immobility time was $17.36 \%$. On the other hand, the yellow banana peel extract $400 \mathrm{mg} \mathrm{kg}^{-1}$ reduces the immobility period by $15.43 \%(153.50 \pm 10.02$, $\mathrm{p}<0.05)$. As for the green banana peel extract $400 \mathrm{mg} \mathrm{kg}^{-1}$, it significantly reduces the duration of immobility to $146.33 \pm 4.68(\mathrm{p}<0.01)$ when compared to control. The percentage of reduction of the immobility time was $19.38 \%$.

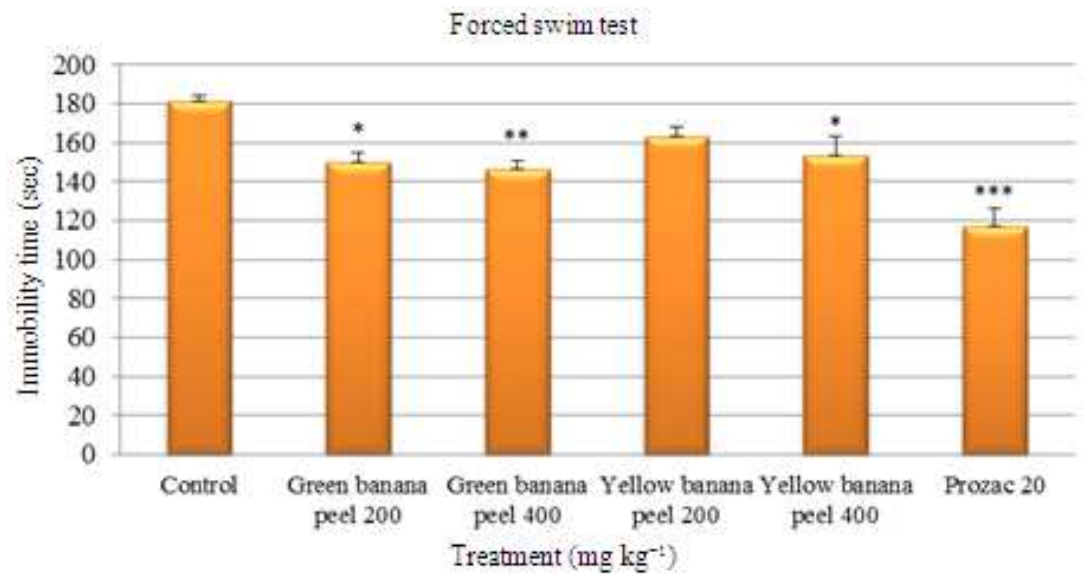

Fig. 1: Effect of treatment on forced swim test in mice. Data represents mean \pm SEM duration of immobility $(n=4-6$ mice per group). Comparison was made using One-way ANOVA followed by Dunnett's multiple comparison tests, $* \mathrm{p}<0.05$ compared with control group, ${ }^{* *} \mathrm{p}<0.01$ compared with control group, $* * * \mathrm{p}<0.001$ compared with control group

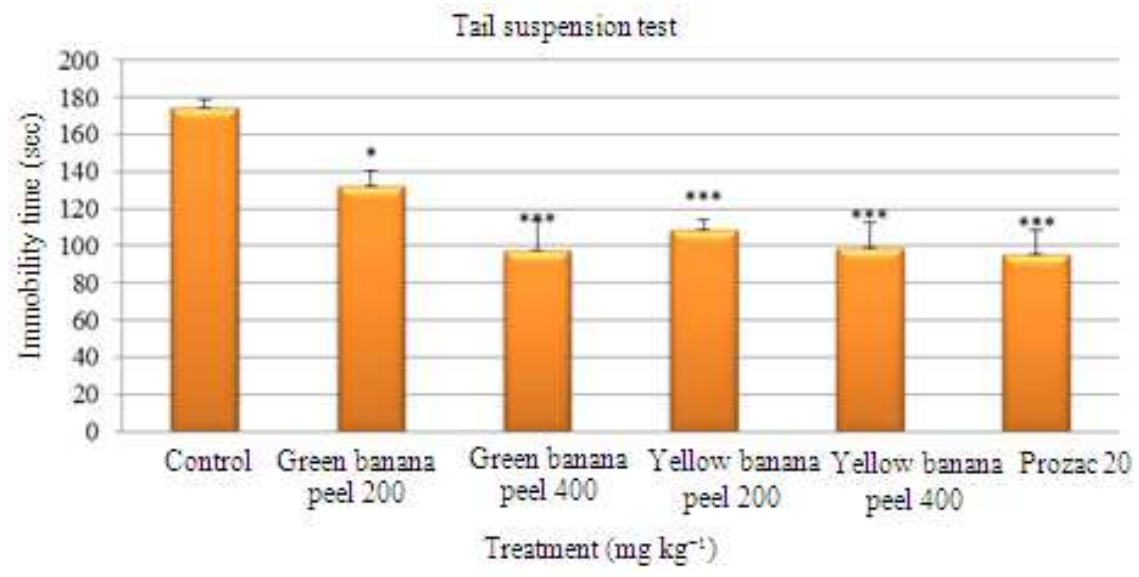

Fig. 2: Effect of treatment on tail suspension test in mice. Data represents mean \pm SEM duration of immobility $(\mathrm{n}=$ 4-5 mice per group). Comparison was made using One-way ANOVA followed by Dunnett's multiple comparison tests, $* \mathrm{p}<0.05$ compared with control group, $* * * \mathrm{p}<0.001$ compared with control group 
Tail suspension test: TST can detect a broad spectrum of antidepressant irrespective of their underlying mechanism (Cryan et al., 2005). TST was reported to have greater sensitivity in detecting SSRIs activity compared to FST (Cryan et al., 2005; Woode et al., 2010) and less stressful than FST (Dhingra and Sharma, 2005; Velraj et al., 2009). Mice in TST shown immediate engage in several agitation or escape-like behaviors when they were suspended in the air followed by temporary increasing bouts of immobility (Woode $e t$ al., 2010). In Fig. 2, oral administration of green banana peel extract $200 \mathrm{mg} \mathrm{kg}{ }^{-1}$ has significant result (132.50 $\pm 8.37, \mathrm{p}<0.05)$, it reduces $24.11 \%$ of the immobility time compared to control. Green banana peel $400 \mathrm{mg} \mathrm{kg}^{-1}$ showed significant effect

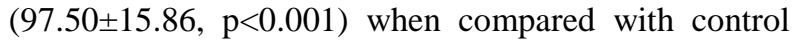
group that were treated with normal saline. The percentage of immobility time reduction was $44.16 \%$. Result also shows that yellow banana peel extract 200 $\mathrm{mg} \mathrm{kg}{ }^{-1}$ and $400 \mathrm{mg} \mathrm{kg}^{-1}$ showed significant result in reducing the immobility time. The immobility time for this two groups were $108.80 \pm 5.68,99.25 \pm 13.84$ $(\mathrm{p}<0.001)$ respectively with the percentage of reduction of the immobility time of $37.69 \%$ and $43.16 \%$. The reduction of immobility time of green banana peel extract $400 \mathrm{mg} \mathrm{kg}^{-1}$ and yellow banana peel extract 400 $\mathrm{mg} \mathrm{kg}{ }^{-1}$ was comparable to Prozac $20 \mathrm{mg} \mathrm{kg}^{-1}$ $(45.36 \%)$, a SSRIs antidepressant drug prescribed as a first line treatment for depression.

\section{CONCLUSION}

It can be concluded that oral administration of both green banana peel extract and yellow banana peel extract at different dose (200 and $\left.400 \mathrm{mg} \mathrm{kg}^{-1}\right)$ can be used to treat depression. Green banana peel extract and yellow banana peel extract does possess antidepressant effects by produces a dose dependant reduction in FST and TST tests. The therapeutic dose for green banana peel extract and yellow banana peel extract in treating depression is $400 \mathrm{mg} \mathrm{kg}^{-1}$. Green banana peel extract were found to be more effective in treating depression compared to yellow banana peel extract. Further research are necessary for locomotor activity study and phytochemical screening for the extract for the better understanding of the actual mechanism of action involved in the antidepressant activity of banana peel. Limit test and pathology examination should be done for acute toxicity study to yield more useful information.

\section{ACKNOWLEDGMENT}

Researchers would like to acknowledge Management and Science University (MSU) and PTPL College for providing the equipment and facilities for this research.

\section{REFERENCES}

American Psychiatric Association DSMV-IV, 2000. Diagnostic and Statistical Manual of Mental Disorders. 4th Edn. Text Revision, American Psychiatric Association, ISBN: 0-89042-025-4, pp: 943.

Badhe, S.R., R.V. Badhe, M.M. Ghaisas, V.V. Chopade and A.D. Deshpande, 2010. Evaluations of antidepressant activity of Anacyclus pyrethrum root extract. Int. J. Green Pharm, 4:79-82. DOI: 10.4103/0973-8258.63880

Bergner, C.L., A.N. Smolinsky, P.C. Hart, B.D. Dufour and R.J. Egan et al., 2010. Mouse models for studying depression-like states and antidepressant drugs. Methods Mol Biol, 602: 267-282. DOI: 10.1007/978-1-60761-058-8_16

Chen, J., W.C. Song and Y.S. Xu, 2007. Study on distilled dietary fiber technology from banana peel. Food Sci., 1: 99-101.

Cryan, J.F., C. Mombereau and A. Vassout, 2005. The tail suspension test as a model for assessing antidepressant activity: Review of pharmacological and genetic studies in mice. Neurosci. Biobehav. Rev., 29 : 571-625. DOI: 10.1016/j.neubiorev.2005.03.009

Department of Health and Ageing, 2003. A manual of mental health care in general practice: Antidepressants.

Dhingra, D. and A. Sharma, 2005. Evaluation of antidepressant-like activity of glycyrrhizin in mice. Int. J. Pharmacol, 6: 390-304. DOI: 10.4103/02537613.19077

Gatsing, D., C.F.N. Nkeugouapi, B.F.N. Nkah, J.R. Kuiate and F.M. Tchouanguep, 2010. Antibacterial activity, bioavailability and acute toxicity evaluation of the leaf extract of Alchornea cordifolia (Euphorbiaceae). Int. J. Pharmacol., 6: 173-182. DOI: 10.3923/ijp.2010.173.182

Gopalakrishna, H.N., S. Rajeshwari, S. Pemminati, S.K. Ashok and M.C. Alwar et al., 2010. A preliminary study on antidepressant activity of NR-ANX-C (a polyherbal product) in mice. J. Pharmacy Res., 3: 550-553. 
Kahn, D.A., M.L. Moline, R.W. Ross, L.S. Cohen and L.L. Altshuler, 2001. Major depression during conception and pregnancy: A guide for patients and families. A Postgraduate Medicine Special Report, pp: 110-111.

Kalra, B.S., V. Tayal and S. Chawla, 2008. Antidepressant-like activity of tramadol in mice. Indian J. Psy., 50: 51-53. DOI: 10.4103/00195545.39760

Khandelwal, S., A.K.M.N. Chowdhury, S.K. Regmi, N. Mendis and P. Kittirattanapaiboon, 2001. Conquering depression. World Health Organization Regional Office for South-East Asia, pp: 6-46.

Mokbel, M.S. and F. Hashinaga, 2005. Antibacterial and antioxidant activities of banana (Musa, AAA cv. Cavendish) fruits peel. Am. J. Biochem. Biotechnol., 1: 125-131.

MPA, 2006. Depression.

Mustaffa, F., J. Indurkar, S. Ismail, M.N. Mordi, S. Ramanathan and S.M. Mansor, 2010. Antioxidant capacity and toxicity screening of Cinnomomum iners standardized leaves methanolic extract. Int. J. Pharmacol., 6: 888-895. DOI: 10.3923/ijp.2010.888.895

NIMH, 2008. Depression. NIH Publication No.083561.

OECD, 2001. OECD guideline for testing of chemicals 423.
Sharma, V.K., N.S. Chauhan, S. Lodhi and A.K. Singhai, 2009. Anti-depressant activity of Zizyphus xylopyrus. Int. J. Phytomed., 1: 12-17.

Sudhakar, P., H.N. Gopalakrishna, A.K. Shenoy, S.S. Sahu and S. Mishra et al., 2010. Antidepressant activity of aqueous extract of Emblica officinalis in mice. Int. J. Applied Biol. Pharm. Technol., 1: 448454.

Velraj, M., A. Vijayalakshmi, S. Jayakumari, S. Ramamoorthy and V. Ravichandiran et al., 2009. Antidepressant activity of the ethanolic extract of Albizzia lebbeck (Linn) bark in animal models of depression. Drug Invent. Today, 1: 112-115.

WHO, 2010. Depression.

Woode, E., E.B. Gyasi, N. Amidu, C. Ansah and M. Duwiejua, 2010. Anxiolytic and antidepressant effects of a leaf extract of Palisota hirsuta K. schum. (Commelinaceae) in mice. Int. J. Pharmacol., 6: 1-17. DOI: 10.3923/ijp.2010.1.17

Woode, E., N. Amidu, W.K.B.A. Owiredu, E. BoakyeGyasi and C. Ansah et al., 2009. Antidepressantlike effects of an ethanolic extract of Sphenocentrum jollyanum pierre roots in mice. Int. J. Pharmacol., 5: 22-29. DOI: 10.3923/ijp.2009.22.29 